\title{
Management in Action: Managing the HIV/AIDS Curriculum in Kenya
}

\author{
Samson Nyarondia ${ }^{1}$, Jared Opiyo Ongong'a ${ }^{1}$, Kepha Omolo ${ }^{2}$ \\ ${ }^{1}$ School of Business and Human Resource Development, Rongo University College, Rongo, Kenya \\ ${ }^{2}$ School of Public Heath, Jaramogi Oginga Odinga University of Science and Technology, Bondo, Kenya \\ Email: rojejaksm@yahoo.com
}

Received 11 May 2014; revised 13 June 2014; accepted 2 July 2014

Copyright (C) 2014 by authors and Scientific Research Publishing Inc.

This work is licensed under the Creative Commons Attribution International License (CC BY).

http://creativecommons.org/licenses/by/4.0/

(c) (i) Open Access

\begin{abstract}
Curriculum management can only be effective when the curriculum content and expected learning outcomes are clearly stated for the actual implementers. The implementers on their side especially the teachers and the school administration must ensure that the stated contents, instructional methodologies and the time lines are followed appropriately. This paper examines the extent at which the HIV/AIDS curriculum is being implemented at the Secondary School level in Kenya. The key objectives were to identify the policy dimensions of HIV/AIDS education curriculum and to determine the level of implementation of HIV/AIDS education curriculum in public secondary schools. Structured questionnaire, observation and in-depth interviews were used for data collection from selected school students and the curriculum implementers. The study concluded that HIV/AIDS aspects are taught in public secondary schools through infusion and integration into carrier subjects, though not allocated any specific time in the curriculum. The level at which these aspects are taught is very low, and when taught lecture method, which is a rather passive way of teaching, is the predominant method employed by the teachers. It is recommended that the teachers should be more creative and devise other forums that would ensure that these aspects are amply taught. Also the teachers should collect and avail more learning materials to their learners, including use of the internet to supplement what is provided in the text books.
\end{abstract}

\section{Keywords}

Management, HIV/AIDS Education, Healthcare Services

\section{Introduction}

Provision of HIV/AIDS education in learning institutions in Kenya, and particularly in the secondary schools, 
has been enhanced by policies set up by the government for more than ten years. The Kenyan government recognized the need to establish clear HIV/AIDS policy guidelines and effective organizational structures several years after 1984, the year when the first case of the disease in the country was reported. In 1996, the leaders of the country began the process that would later culminate into formulation of HIV/AIDS curriculum to be used in schools, by first developing a draft national HIV/AIDS policy which was submitted to Parliament. The draft policy was approved in September 1997 as Sessional Paper No. 4 of 1997 on AIDS in Kenya [1].

The goal of the Sessional Paper was to provide a policy framework within which AIDS prevention and control efforts would be undertaken in future. According to the paper, effective response to the HIV/AIDS crisis would require a strong political commitment at the highest level with priority focus on young people.

Some of the key aspects of the policy framework outlined in the Sessional Paper include: schools to provide support for activities that reduce the risk of HIV infection through promoting basic education on HIV and STIs and encouraging the youth to delay onset of sexual activity. It also lays emphasizes on promotion of socio-cultural norms, values and beliefs that would help reduce the risk of HIV transmission and highlights on the need for religious consensus on teachings about sexuality and socio-cultural practices. Lastly, the paper stipulates that the government should design morally and scientifically acceptable HIV/AIDS education program for the youth in and out of school and advocates for their protection against anti-social behavior that puts them at risk.

\subsection{Purpose of the Study}

The purpose of the study was to investigate the implementation of HIV/AIDS education curriculum in public secondary schools in Kenya.

\subsection{Specific Objectives}

The specific objectives of the study were to:

(i) Identify the policy dimensions of HIV/AIDS education curriculum that are being implemented in public secondary schools in Kisumu West District.

(ii) Determine the level of implementation of HIV/AIDS education curriculum in public secondary schools in Kisumu West District.

\section{Literature Review}

\subsection{Aspects of HIV/AIDS Taught}

A needs assessment was conducted in Oyo State, Nigeria in 1998 on HIV/AIDS Education [2]. The assessment was done in 131 project secondary schools by the Ministry of Education, Science and Technology. Data collection was done by focused group discussions and questionnaires completed by teachers, parents, and students. The results showed that the following aspects were taught in HIV/AIDS education: Sexual and Reproductive Health, STIs and HIV/AIDS, Life Skills, Values/Attitudes, Social and Cultural Context of HIV/AIDS, Gender, Stigmatization and Discrimination.

A study in Dominican Republic found out that HIV/AIDS education was rather broad and included even aspects of sex education in public secondary schools. The aspects taught included: Sexual and Reproductive Health, Prevention of HIV, Responsible Sexual Behavior (responsibility toward oneself and others), Sexual Behavior from an Emotional Perspective, Self-Efficacy and Self-Esteem, Responses to Peer Pressure, Interpersonal Communication Skills, Negotiating Skills and the Right to Say No to Sex (with emphasis on the rights of girls). Students were also provided with information on contraception, including the use of condoms as a means to prevent HIV and other STIs.

\subsection{Time Allocation to HIV/AIDS Teaching}

A study [3] revealed that in Zimbabwean secondary schools, HIV/AIDS education was taught through infusion whereby teachers were encouraged to incorporate its contents in other subjects wherever opportunities arose without allocating for it any specific amount of time.

According to Catholic Relief Services [4], HIV/AIDS education in Gambian schools was based on a module within a carrier subject known as Population and Family Life Education (POP/FLE) and was taught to learners in primary and secondary schools. All the learners were taught POP/FLE for forty five minutes a week in pri- 
mary schools and one hour minutes a week in secondary schools. On the other hand, in secondary schools within Oyo State, Nigeria, HIV/AIDS was taught once or twice a week for one hour during biology lesson and discussed for at least five minutes a week by various subject teachers during their regular lessons [5].

In Britain, the needs assessment done [6] on implementation of HIV/AIDS curriculum in high schools did not mention the amount of time taken to teach HIV/AIDS per week, arguing that since it was taught through infusion in the carrier subjects, it was not easy to quantify the amount of time allocated for teaching it alone. However, $63 \%$ of the students are reported of having utilized only 1 - 5 hours for HIV instruction throughout their entire high school education.

Okenye [7] conducted a study on Implementation of HIV/AIDS syllabus in primary schools in Londiani Division, Kericho District in Kenya. Explorative descriptive survey design was used in which semi-structured questionnaires were administered to both teachers and pupils. Cluster sampling was used to arrive at the appropriate sample. She used both quantitative and qualitative techniques for data analysis. In her findings, a total of $66 \%$ of the pupils and $67 \%$ of the teachers said that the subject was taught once a week; while the rest reported that it was taught very rarely.

\subsection{Teaching Methods}

Caceres [8] conducted a study in Lima, Peru among 1213 students in 14 secondary schools. Their study was experimental in design. They found out that those participatory teaching methods such as discussions, role playing, verbal exercises and familiarization with condoms were frequently used in teaching HIV/AIDS. Likewise, the Ministry of Education, Science and Technology of Oyo State in Nigeria carried out a study which found out that the teaching of HIV/AIDS in secondary schools within the state was through drama, songs, dance, role-plays, storytelling, group discussions, and presentations [9]. In Dominican Republic, however, the main method for teaching HIV/AIDS was found to be lecture method.

\subsection{HIV/AIDS Education and Learning Resources}

According to Bholah and Gunga [10], Mauritius Institute of Education (MIE) adopted infusion approach in secondary schools in the whole country in which students studying Biology studied HIV/AIDS topics. The MIE initiated a link with all the schools in the island using a blended mode of face-to-face and online interaction of HIV/AIDS course designed for students. A CD-ROM with all the learning resources on HIV/AIDS was provided to both students and teachers to enhance students' understanding of HIV/AIDS concepts. The institute purposely used these learning resources with an aim that they would eventually prevent any spread of the disease among students in the schools and help the society at large.

As well, a report by International Bureau of Education [11] about HIV/AIDS education in Ghana shows that it has been infused into the school curriculum at all secondary school levels in a range of carrier subjects including Environmental Studies, Integrated Science, Life Skills and Agricultural Science. Some of the learning resources included use of text books of the various carrier subjects and radio which offers HIV/AIDS school programs infused in various subjects.

\subsection{Literature Gaps}

The body of literature above shows that certain issues have not been considered by the previous studies which this study sought to address. While studies by IBE [16] and others outlined the HIV/AIDS aspects taught in schools, they did not clearly show the extent to which each aspect was being taught. This study attempted to reveal the relative preference given to each HIV/AIDS aspect depending on the frequency and amount of time given to each one.

The variables are subsequently compared with the national targets and standards of teaching HIV/AIDS education as stipulated in the Education Sector HIV/AIDS Policy document. The variables involved in this study are illustrated in Figure 1.

\section{Methodology}

\subsection{Study Design}

Descriptive cross-sectional survey design has been appropriate for this study since it allows generalization from 
BACKGROUND VARIABLE

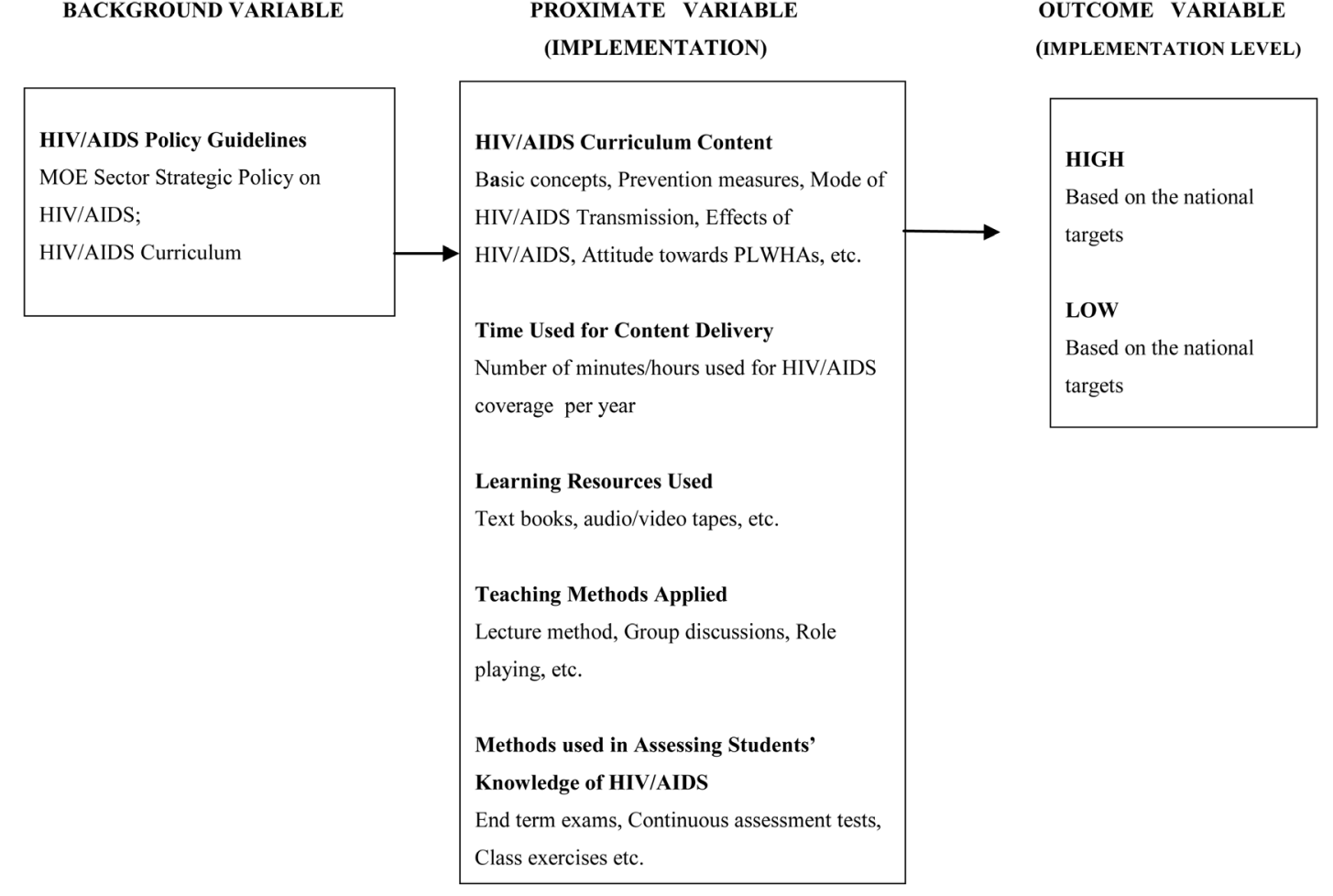

Figure 1. Conceptual framework.

a sample to a population [12]. Preference was also given to this design due to the fact that it necessitates a comparatively quick and cheap data collection [13] and yields a great deal of accurate information [14].

The study also involved quantitative and qualitative methods. Quantitative method is exhibited by data collected through use of structured questionnaire. On the other hand, the design is qualitative since some of the data was collected by observation and in-depth interviews. The variables used in the study were: aspects of HIV/ AIDS taught; time taken to teach HIV/AIDS; teaching methods of HIV/AIDS education; learning resources and assessment of HIV/AIDS education in the secondary schools.

\subsection{Ethical Considerations}

Permission for data collection was sought from MOEST through Kisumu West District Education Officer and the head teachers of the schools sampled for study. Letters of introduction from the DEO and Great Lakes University of Kisumu were acquired before going to the head teachers of the sampled schools to seek permission for collection of data from their schools. The researcher then took the letters of introduction personally to the head teachers of the sampled schools, requesting them to allow him to use the schools for the purpose of the study. This was done two weeks before the intended day of undertaking the study to ensure that the authorities of the schools found appropriate time for the data collection exercise.

\section{Study Findings}

\subsection{Aspects of HIV/AIDS Taught}

More than half of the teachers of HIV/AIDS in the public secondary schools covered three out of the seven recommended topics in the five carrier subjects. The topics include Basic Concepts of HIV/AIDS that 45 (75\%) teachers reported to have covered, Modes of Transmission indicated and to have been taught by 51 (85\%) and Prevention Measures which was taught by 43 (72\%) teachers. The topic of Religious and Cultural Beliefs was only taught in English. Likewise, attitude towards People Living with HIV/AIDS was only taught in CRE. These results show that the aspects of HIV/AIDS taught are more or less similar to those taught in Nigeria as revealed by International Bureau of Education except for Life Skills, Gender and Stigmatization, which are not included 
in the Kenyan HIV/AIDS curriculum for secondary schools.

\subsection{Time Taken in Teaching HIV/AIDS Education}

The study reveals that no specific amount of time has been allotted in the curriculum for covering the aspects of HIV/AIDS education through infusion and integration approach in the study area. This was also the case in Zimbabwean secondary schools [15] and high schools in Britain [16]. This has made teaching HIV/AIDS aspects in the study district very minimal and irregular since most teachers view it as optional.

\subsection{HIV/AIDS Teaching Methods}

The study found out that the dominant method applied by teachers in teaching HIV/AIDS in the schools within the district is lecture method. Although the rate of use of the teaching method varied from one carrier subject to another, this teaching method still was used often than the interactive methods such as group discussion and role plays. This seems to be in contrast with the other previous findings [17] and [18], in which the teaching methods that allowed more student participation in the learning of HIV/AIDS such as discussions, role playing, drama, songs and familiarization with condoms were frequently used than lecture method.

\subsection{Types of Learning Resources in Teaching HIV/AIDS Education}

The findings reveal that the main learning resources used in teaching HIV/AIDS education are class texts of the various carrier subjects. These were followed by use of newspapers and magazines which in most cases were not used during class hours but at the students' free time.

\subsection{Methods of Assessing Students on HIV/AIDS Education}

Majority 37 (62\%) of the teachers indicated that they examined students on HIV/AIDS aspects. Twenty (54\%) of the teachers who examined it indicated that this was done in the form of continuous assessment tests, 8 (22\%) gave students class exercises and $2(5 \%)$ tested it in end term examinations within the carrier subjects. Only 7 $(19 \%)$ of the teachers who indicated that they assessed HIV/AIDS aspects said that they did so by use of all the above mentioned methods. They also admitted that this was done very irregularly. They indicated that a question on HIV/AIDS aspect could occasionally be included in the test of a carrier subject, since much preference is given to core contents of the carrier subjects. This means that there is some element of formal assessment of HIV/AIDS in the schools in the district.

\section{References}

[1] MOEST (1999) The HIV Syllabus for Schools and Colleges. Kenya Institute of Education, Nairobi.

[2] International Bureau of Education (2006) Manual for Integrating HIV/AIDS Education in School Curricula, Vol. 2-Assessment of the Current Situation. UNESCO, Geneva.

[3] O’Donoghue, J. (1995) Zimbabwe’s AIDS Action Programme for Schools. UNICEF, Harare.

[4] Catholic Relief Services (2003) Study on the Perceptions about PLHA among School Children in Upper Basic, Basic Cycle and Secondary Schools within the Catholic Diocese of Banjul. Catholic Relief Services, Banjul.

[5] International Bureau of Education (2006) Manual for Integrating HIV/AIDS Education in School Curricula, Vol. 2-Assessment of the Current Situation. UNESCO, Geneva.

[6] Lee, R., Piya, S., Michelle, S. and Jessica, Z. (2006) Developing an HIV Curriculum for High School Students: Needs Assessment and Conceptualization, Stanford University. Stanford University, Research Compliance Office, UK.

[7] Okenye, E.M. (2004) Implementation of HIV/AIDS Syllabus in Primary Schools: A Case Study of Londiani Division. Unpublished P.G.D.E. Thesis, Kenyatta University, Kenya.

[8] Caceres, C.F., Rosasco, A.M., Mandel, J.S. and Hearst, N. (1994) Evaluating a School-Based Intervention for STD/ AIDS Prevention in Peru. Journal of Adolescent Health, 15, 582-591. http://dx.doi.org/10.1016/1054-139X(94)90143-Q

[9] International Bureau of Education (2006) Manual for Integrating HIV/AIDS Education in School Curricula, Vol. 2-Assessment of the Current Situation. UNESCO, Geneva.

[10] Bholah, R. and Gungadeen, A. (2009) Online HIV/AIDS Education: A Doorway to an Innovative Teaching and 
Learning Approach. Mauritius Institute of Education.

[11] International Bureau of Education (2006) Manual for Integrating HIV/AIDS Education in School Curricula, Vol. 2Assessment of the Current Situation. UNESCO, Geneva.

[12] Babbie, E. (1990) Survey Research Methods. 2nd Edition, Wadsworth, Belmont.

[13] Grinnel, M.R.J. (1993) Social Work, Research and Evaluation. 4th Edition, F.E. Peacock Publishers, Inc., Illinois.

[14] Gay, R.L. (1976) Educational Research Competencies for Analysis \& Application. Merill Publishing Co., Ohio.

[15] O’Donoghue, J. (1995) Zimbabwe’s AIDS Action Programme for Schools. UNICEF, Harare.

[16] Lee, R., Piya, S., Michelle, S. and Jessica, Z. (2006) Developing an HIV Curriculum for High School Students: Needs Assessment and Conceptualization, Stanford University. Stanford University, Research Compliance Office, UK.

[17] Caceres, C.F., Rosasco, A.M., Mandel, J.S. and Hearst, N. (1994) Evaluating a School-Based Intervention for STD/ AIDS Prevention in Peru .Journal of Adolescent Health, 15, 582-591.

[18] International Bureau of Education (2006) Manual for Integrating HIV/AIDS Education in School Curricula, Vol. 2Assessment of the Current Situation. UNESCO, Geneva. 
Scientific Research Publishing (SCIRP) is one of the largest Open Access journal publishers. It is currently publishing more than 200 open access, online, peer-reviewed journals covering a wide range of academic disciplines. SCIRP serves the worldwide academic communities and contributes to the progress and application of science with its publication.

Other selected journals from SCIRP are listed as below. Submit your manuscript to us via either submit@scirp.org or Online Submission Portal.
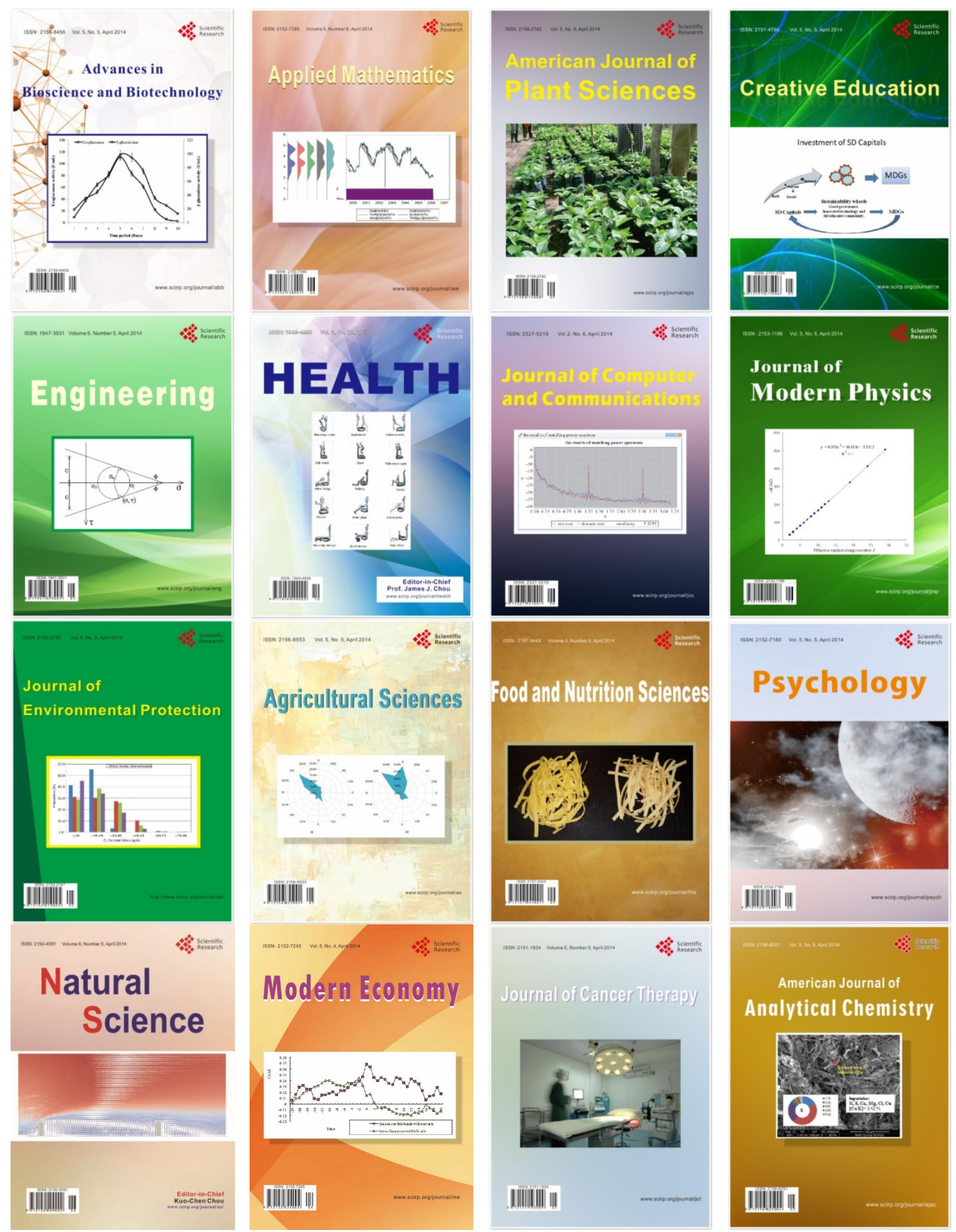